\title{
Loss of Heterozygosity Suggests Multiple Genetic Alterations in Pheochromocytomas and Medullary Thyroid Carcinomas
}

\author{
S. Khosla, * V. M. Patel," I. D. Hay," D. J. Schaid, ${ }^{\star}$ C. S. Grant," J. A. van Heerden," and S. N. Thibodeau" \\ Departments of *Endocrinology and Internal Medicine, ${ }^{\ddagger}$ Oncology, ${ }^{\S}$ Surgery, and $"$ Laboratory Medicine, \\ Mayo Clinic and Mayo Foundation, Rochester, Minnesota 55905
}

\begin{abstract}
Loss of heterozygosity (LOH) at specific loci may help localize tumor suppressor genes involved in the formation of various familial and sporadic tumors. In addition, the genetic loci for a number of familial tumor syndromes have been mapped by linkage analysis. To explore the possible role of tumor suppressor genes in endocrine tumors, we tested 41 pheochromocytomas (34 sporadic and 7 familial) and 11 medullary thyroid cancers (MTC) (10 sporadic and 1 familial) for LOH near a variety of potentially important genetic loci: $(a)$ the multiple endocrine neoplasia type 2A (MEN 2A) locus on chromosome 10; (b) the von Hippel-Lindau locus on $3 p$; and (c) the p53 and neurofibromatosis 1 loci on 17. We also examined chromosomes $1 p$ and $22 q$ because previous studies in a small number of pheochromocytomas and MTCs suggested LOH in these regions. Background rates for $\mathrm{LOH}$ were assessed using several "random" probes. Finally, we examined a number of clinical and histologic characteristics of these tumors for possible correlations with specific genetic alterations. $\mathrm{LOH}$ in the region of the MEN 2A locus was uncommon (0\% for MTCs, 5\% for pheochromocytomas). However, we found significant allelic losses in pheochromocytomas on chromosomes 1p (42\%), 3p $(16 \%), 17 p(24 \%)$, and $22 q(31 \%)$. We also noted a correlation between LOH on $1 p$ and urinary excretion of metanephrine by these patients $(P=0.02)$. LOH on $1 p, 3 p$, and $17 p$ also appeared to be associated with increased tumor volume. Analysis of the smaller number of MTCs demonstrated allelic losses on chromosomes 1p and 22q. Our results suggest that tumor formation and/or progression in pheochromocytomas and MTCs involves multiple genes, analogous with the model proposed for colon carcinoma. (J. Clin. Invest. 1991. 87:1691-1699.) Key words: allelic losses $\bullet$ tumor suppressor genes $\bullet$ multiple endocrine neoplasia $\bullet$ familial tumors • tumorigenesis
\end{abstract}

\section{Introduction}

The inactivation of tumor suppressor genes is thought to be important in the pathogenesis of many human cancers (1). The prototypic model for tumor suppressor genes is the retinoblas-

Presented in part at the 31 October 1990 Midwestern Section Session of the American Federation for Clinical Research.

Address reprint requests to Dr. Sundeep Khosla, Endocrinology and Internal Medicine, Mayo Clinic, Rochester, MN 55905.

Received for publication 27 September 1990 and in revised form 28 November 1990.

J. Clin. Invest.

(c) The American Society for Clinical Investigation, Inc $0021-9738 / 91 / 05 / 1691 / 09 \quad \$ 2.00$

Volume 87, May 1991, 1691-1699 toma ( $R B 1)^{1}$ gene, which has been cloned and sequenced (2). Retinoblastoma can occur either in a hereditary or a sporadic form. In the hereditary form of the disease, one RB1 allele is abnormal in the germ line and the second allele is inactivated as a somatie event. In the sporadic form, both RB1 alleles are inactivated in somatic cells, leading to tumor formation (3). Thus, similar genetic mechanisms are involved in both forms of the disease, with tumors occurring at a far higher frequency in the familial form since fewer somatic mutations are required for tumor formation (3).

In contrast to the RB1 gene, the sequences of other tumor suppressor genes are unknown. The chromosomal locations of candidate tumor suppressor genes are inferred, however, based on the detection of somatic allelic losses in various tumors. Combined with linkage analysis, such an approach has led to the localization of several cancer-predisposing genes, such as the genes for multiple endocrine neoplasia type 1 (MEN 1) (4), MEN 2A (5, 6), neurofibromatosis 2 (NF 2) (7), von HippelLindau disease (VHL) (8), and familial adenomatous polyposis (FAP) of the colon $(9,10)$.

Like retinoblastoma, pheochromocytoma and medullary thyroid carcinoma (MTC) can occur in both familial and sporadic forms. Both are components of the MEN 2A syndrome, which has been mapped to the centromeric region on chromosome $10(5,6)$. In contrast to retinoblastoma, however, allelic loss on chromosome 10 near the MEN 2A locus has been an uncommon event in these tumors $(11,12)$. This has led to speculation that the MEN 2A gene may not be entirely analogous to the RB1 gene (12). In retinoblastoma, the inherited mutation in familial cases is typically a small deletion or, presumably, a point mutation. The loss of the second allele in a tumor cell, in contrast, often involves loss of a large piece of DNA, detectable by a loss of heterozygosity $(\mathrm{LOH})$ analysis. In this model, it appears that both copies of the RB1 gene need to be inactivated for phenotypic effects $(1,3)$. In contrast to retinoblastoma, in other familial cancer syndromes phenotypic effects could result from the loss or inactivation of only one copy of the putative tumor suppressor gene (1). Indeed, this appears to be the case for FAP, which has been mapped to chromosome $5 q(9,10)$. In that syndrome, generalized colonic epithelial hyperplasia occurs without loss of the wild-type allele, presumably reflecting a gene dosage effect of the FAP gene (13). In FAP, genetic changes at other loci involving chromosomes $12 \mathrm{p}, 18 \mathrm{q}$, and $17 \mathrm{p}$, and possibly others, are then thought to contribute to the transition to malignancy (13). Because LOH near the MEN 2A locus has not been found in familial pheochromocytomas and MTCs, a model similar to that for

1. Abbreviations used in this paper: FAP, familial adenomatous polyposis; $\mathrm{LOH}$, loss of heterozygosity; MEN, multiple endocrine neoplasia; MTC, medullary thyroid cancer; NF, neurofibromatosis; RB1, retinoblastoma; VHL, von Hippel-Landau. 
FAP has been proposed for MEN 2A-associated tumors (12). A prediction of this model would be the presence of genetic alternations in pheochromocytomas and MTCs at several loci other than the MEN 2A locus, in close analogy with FAP and colon carcinoma.

In these studies, we tested the above prediction by examining a large number of pheochromocytomas and MTCs for allelic losses at several potentially important genetic loci. In addition to the MEN 2A locus on chromosome 10, we also examined chromosomes $1 p$ and $22 q$ because previous studies in a small number of tumors had suggested $\mathrm{LOH}$ for various markers in these regions (14-16). Since pheochromocytomas are also found in VHL disease and NF 1, we also tested the pheochromocytomas for $\mathrm{LOH}$ on chromosomes $3 p$ and 17 , where the genes for these syndromes have been mapped or, in the case of NF 1 , recently cloned $(8,17,18)$. Our results support the hypothesis that multiple genetic alterations on chromosomes $1 p, 22 q, 17 p$, and $3 p$ may be involved in the development of pheochromocytomas. Based on a clinical analysis of the pheochromocytomas, our studies further suggest a relationship between specific genetic changes and certain clinical characteristics of the tumors.

\section{Methods}

Clinical material. Tumors and peripheral blood leukocyte DNA were analyzed from 41 patients with pheochromocytoma and 11 with MTC. Table I summarizes the pertinent clinical characteristics of the patients. Of the 41 pheochromocytoma patients, 34 had sporadic tumors and 7 had familial disease (2 MEN 2B, 2 NF 1, 1 MEN 2A, 1 VHL, and 1 familial pheochromocytoma alone). Of the 11 MTC patients, 10 had sporadic disease and 1 was part of a kindred with familial MTC only.

We obtained pheochromocytoma and MTC tissue at the time of surgery and stored them at $-70^{\circ} \mathrm{C}$. For the control experiments examining $\mathrm{LOH}$ on chromosome $1 \mathrm{p}$, we obtained 20 colon carcinomas and samples of adjacent normal mucosa, and 10 osteosarcomas. Peripheral blood leukocytes were obtained from all patients for constitutional DNA. All tumor tissue was serially sectioned using a cryostat and only sections showing $>70 \%$ tumor cells were used for DNA extraction.

DNA methods. High molecular weight DNA was isolated from both tissues and peripheral blood leukocytes using an Applied Biosystems, Inc., Foster City, CA 340A nucleic acid extractor. DNA $(2.5 \mu \mathrm{g})$ was digested with a restriction enzyme, electrophoresed on a $0.8 \%$ agarose gel, and transferred to a nylon membrane (MSI) according to the method of Southern (19). The membranes were then hybridized to a number of DNA probes $(20-33)$ which were labeled with ${ }^{32} \mathrm{P}$ by random priming (Amersham Corp., Arlington Heights, IL) (Table II). A

Table I. Description of Study Patients and Their Tumors

\begin{tabular}{|c|c|c|}
\hline & Pheochromocytomas & $\begin{array}{c}\text { Medullary } \\
\text { thyroid carcinomas }\end{array}$ \\
\hline Number of patients & 41 & 11 \\
\hline Age median $(y r)$ & 42 & 51 \\
\hline (range) & $(12-72)$ & $(32-76)$ \\
\hline Sex: male & $34 \%$ & $45 \%$ \\
\hline female & $66 \%$ & $55 \%$ \\
\hline Sporadic & $83 \%$ & $91 \%$ \\
\hline Familial & $17 \%$ & $9 \%$ \\
\hline Ploidy status: Diploid & $32 \%$ & 0 \\
\hline Nondiploid & $41 \%$ & 0 \\
\hline Unknown & $27 \%$ & $100 \%$ \\
\hline
\end{tabular}

locus was considered informative for a particular patient when the constitutional DNA from that patient displayed two different alleles (i.e., heterozygosity at that locus). LOH was scored only if there was absence or marked reduction in the intensity of one of the two allele bands (Fig. 1). In addition, visually assessed allele loss was confirmed by scanning densitometry. For all of the two allele probes, the residual absorbance of the deleted band in tumor DNA was normalized against the absorbance of the retained band in order to adjust for DNA content. The band in constitutional DNA corresponding to the deleted band in tumor DNA was similarly normalized. The normalized intensity of the deleted band in tumor DNA was then divided by the normalized intensity of the corresponding band in constitutional DNA to obtain a relative intensity value. As shown in Fig. $2 a$, when this analysis was applied to any band from a negative tumor, the relative intensity of this band in comparison to the corresponding band in peripheral leukocyte DNA was $\sim 1.0$. In contrast, all bands scored visually as being deleted had residual intensities varying from 0.0 to 0.3 . Presumably, the residual signal results from the presence of contaminating normal DNA from stromal cells and/or infiltrating leukocytes, although the possibility of tumor heterogeneity, with presence of a neoplastic population lacking allelic loss, cannot be ruled out.

The above densitometric analysis had to be modified somewhat in order to analyze the results of the p1-79 probe. This probe provides a fingerprint pattern with $20-40$ bands. The high interindividual variability of this probe is related to the presence of different copy numbers of a core sequence spanning 39-40 bp (21). LOH with this probe is scored as positive when one or more bands are deleted in tumor DNA (Fig. 1 a) $(34,35)$. As noted by Genuardi et al. (34) in their analysis of breast cancers with the pl-79 probe, the banding pattern in constitutional DNA consists of a combination of bands. Some bands are unique to each of the two chromosomes whereas others are common to both chromosomes. With allelic loss, one typically sees loss of bands which are specific for the deleted chromosome. In addition, bands which are common to both chromosomes are reduced in intensity by $50 \%$. Finally, bands unique to the retained chromosome remain unchanged in intensity. This is illustrated in Fig. $3 a$, which is a densitometric scan of the p1-79 (Taq 1) blot shown in Fig. $1 a$. As is evident, band $D$, which corresponds to the arrow in Fig. $1 a$, is deleted in tumor DNA. In addition, relative to band $A$, multiple other bands are reduced in intensity. Band $A$ thus represents a band unique to the retained chromosome, whereas bands $B$ and $C$ represent bands common to both chromosomes. Band $D$, in contrast, is unique to the deleted chromosome and absent in tumor DNA. When the intensities of bands $B$ and $C$ are normalized against band $A$ in tumor and normal DNA and the relative

Table II. Description of Probes Used to Test for Allelic Loss

\begin{tabular}{llllc}
\hline \multicolumn{1}{c}{ Probe } & $\begin{array}{c}\text { Restriction } \\
\text { endonuclease }\end{array}$ & \multicolumn{1}{c}{ Locus } & $\begin{array}{c}\text { Chromosomal } \\
\text { localization }\end{array}$ & References \\
\hline AF3 & PvuII & FUCA1 & 1p34-p35 & 20 \\
p1-79 & PstI & DIZ2 & 1p36.3 & \\
p1-79 & TaqI & DIZ2 & 1p36.3 & 21 \\
pYNH24 & TaqI & D2S44 & 2pter-q32 & 22 \\
H3H2 & HindIII & DNF1552 & 3p21 & 23 \\
p627 & TaqI & RAF1 & 3p25 & 24 \\
M4 & BamH1 & D5S6 & 5q11.2-q13.3 & 25 \\
H-4IRBP & StyI & RBP3 & $10 q 11.2$ & 26 \\
pMCK2 & PvuII & D10S15 & 10q 11.2 & 27 \\
p88R0.6 & XbaI & RB1 & 13q 14.2 & 28 \\
p3'HVR & PstI & D16S85 & 16p 13.3 & 29 \\
pYNZ22.1 & BamH1 & D17S5 & $17 p 13.3$ & 30 \\
pTHH59 & TaqI & D17S4 & 17q23-q25.3 & 31 \\
p22-34 & TaqI & D22S9 & 22q11.1-q11.2 & 32 \\
pMS3-18 & Bg1II & D22S1 & 22q11.12-qter & 33 \\
& & & & \\
\hline
\end{tabular}



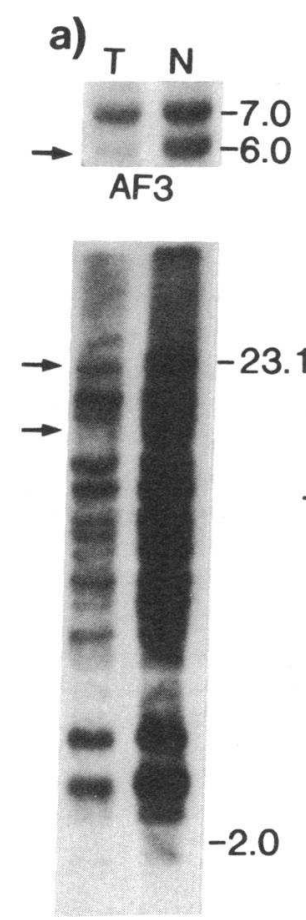

p1-79(Pst 1) b)

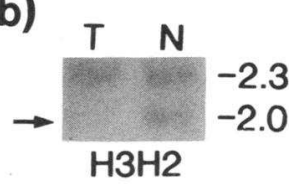

T N

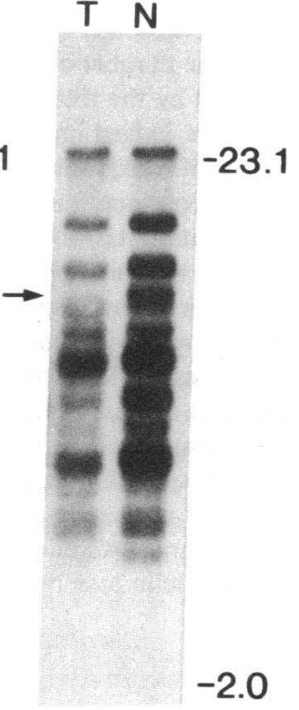

d)

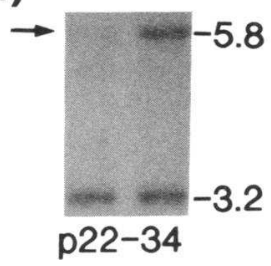

c)

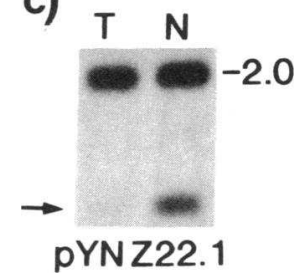

intensity values calculated, it is clear that bands $B$ and $C$ are reduced in intensity by $\sim 50 \%$. Fig. $3 b$ shows the corresponding densitometric plots from a tumor scored visually as negative. In this scan, every peak in normal DNA has a corresponding peak in tumor DNA with the relative intensities of all peaks remaining the same. We therefore confirmed allelic loss in all our positive tumors by performing densitometric scans on the autoradiograms and demonstrating each of the following: $(a)$ the presence of retained bands relative to which numerous other bands were reduced in intensity; $(b)$ the presence of unequivocally deleted bands with residual relative intensity values of $<30 \%$; and (c) the presence of common bands which were reduced in relative intensity by $50 \%$. This is summarized in Fig. $2 b$ which also indicates that such an analysis on a sample of tumors scored visually as negative gave relative intensity values of any given band in tumor DNA of $\sim 1.0$.

$N$-myc gene amplification. We performed analysis for possible $N$ $m y c$ gene amplification with the $N$-myc probe pNB-1, using the restriction endonuclease EcoRI (36). The membranes were concomitantly hybridized with a known single copy marker, KM.19 (locus D7S23, 7q31-q32) (37). The signal for pNB-1 was normalized against that for

KM.19 and $N$-myc amplification scored only if there was $\geq 2$-fold increase in the above ratio.

Nuclear DNA ploidy status. The study material consisted of paraffin-embedded tissue blocks of the pheochromocytomas. Hematoxylin and eosin stained slides were made of 6- $\mu \mathrm{M}$ thick sections from the front and back of each pheochromocytoma block analyzed. These slides were all examined by a pathologist to ensure the presence of tumor tissue in the $40-\mu \mathrm{M}$ thick sections used for analysis of DNA content. Nuclear suspensions were prepared for the paraffin-embedded tissue blocks and the isolated nuclei stained with propidium iodide by standard methods (38). Nuclear DNA content was measured on a FACS ${ }^{\circledR}$ IV flow cytometer (Becton Dickinson \& Co., Mountain View, CA), connected with a computer programmed to perform cell cycle analysis according to the method of Dean and Jett (39). The DNA histogram patterns were then analyzed and classified as either DNA normal (diploid) or DNA nondiploid.

Clinical analysis. The clinical histories for all the MTC and pheochromocytoma patients were reviewed and the following information was extracted: sex, age, benignancy versus malignancy of the tu-

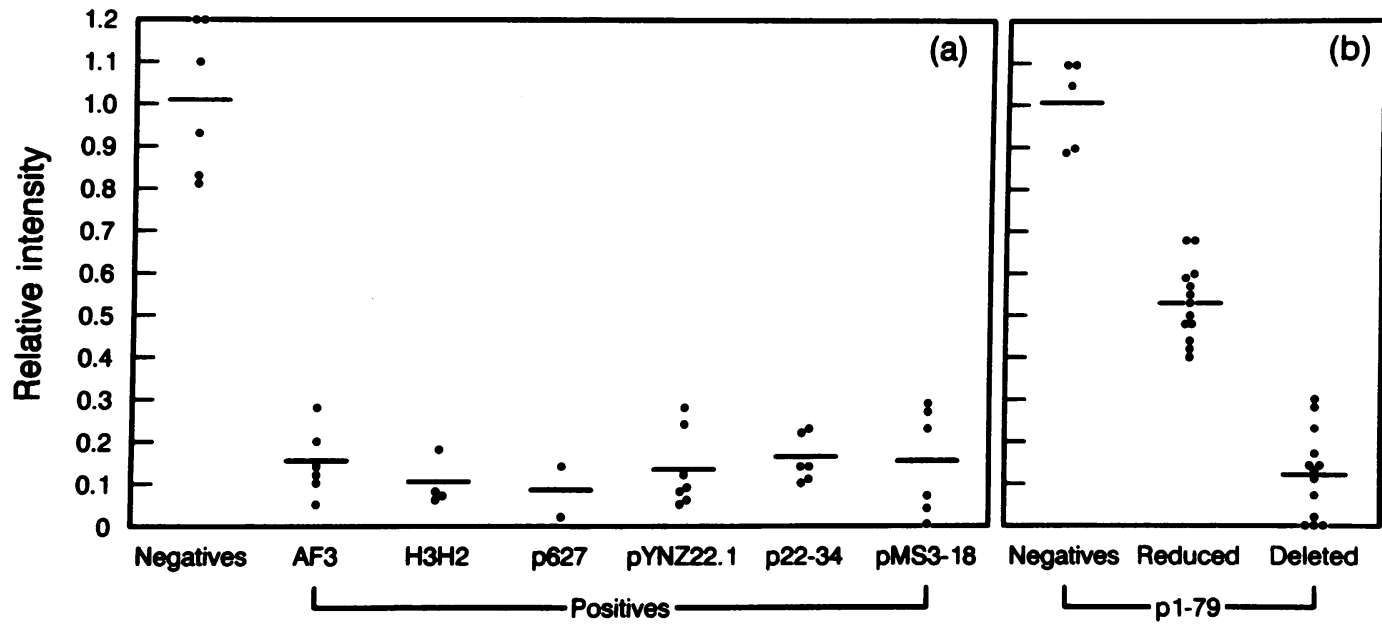

Figure 2. Densitometric analysis of tumors. Horizontal lines represent the mean values for relative intensity. (a) Two allele probes; and $(b)$ the fingerprint probe p1-79. 


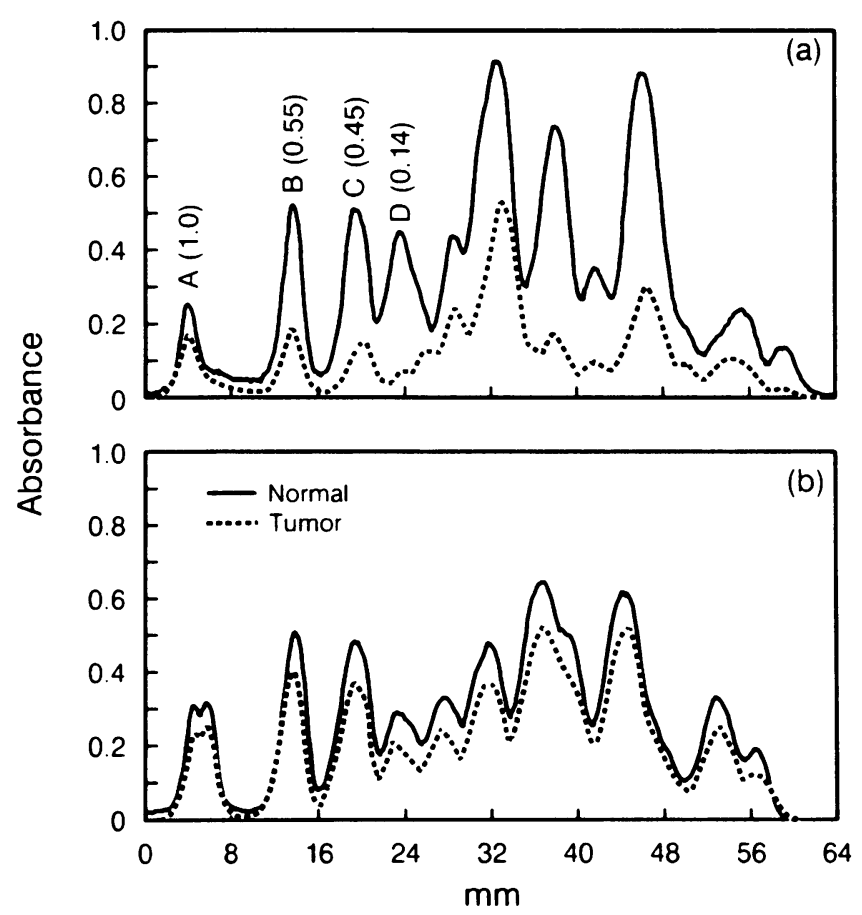

Figure 3. (a) Densitometric scan of the autoradiogram shown in Fig. 1 $a$ for the p1-79 (Taq 1) blot. This tumor was scored visually as positive. Solid line represents the normal DNA autoradiogram and the dashed line represents the tumor DNA autoradiogram. Numbers in parentheses next to bands $A, B, C$, and $D$ are the calculated relative intensities of the bands in tumor DNA versus constitutional DNA, based on a normalization against the preserved band $A$; and $(b)$ densitometric scan of an autoradiogram from a tumor scored visually as negative for allelic loss. mor, familial versus sporadic tumor, tumor volume, nuclear ploidy status, preoperative plasma calcitonin level (MTC), or preoperative urine metanephrine (pheochromocytomas).

Statistical methods. The incidence of allelic loss was calculated by dividing the number of tumors demonstrating loss by the total number of tumors informative with a particular probe. Where more than one probe was used in a given chromosomal region, an aggregate percentage was calculated. For this, the number of tumors demonstrating loss with either probe was divided by the total number informative with either probe. For our data, we judged an incidence of $3 \%$ to be the highest anticipated incidence of background loss (see below and Table III). For each probe/enzyme combination, we report $P$ values, computed by the binomial distribution, testing whether the observed incidence was significantly greater than a background loss of $3 \%$. We also report $95 \%$ confidence intervals to demonstrate the range of percentage allelic loss which is consistent with our data.

The association of allelic loss on chromosomes $1 p, 3 p, 22 q$, and $17 p$ with patient demographic and clinical characteristics was assessed by use of Fisher's exact test for contingency tables when patient characteristics were dichotomous (sex, sporadic versus familial, diploid versus nondiploid). The distributions of continuous characteristics (age, tumor volume, urinary metanephrine excretion) were compared between patients with and without allelic loss by the Wilcoxon rank sum statistic.

\section{Results}

Chromosome 10 losses. As noted in earlier studies $(11,12)$, LOH in the region of the MEN 2A locus was found to be an uncommon event both in the pheochromocytomas and the MTCs (Tables III and IV). Only 1 of 22 informative pheochromocytomas $(5 \%)$ demonstrated allelic loss in that region. None of the 7 informative MTCs were positive. None of the 3 pheochromocytoma patients with MEN 2 were informative with either chromosome 10 marker. Thus, our results include

Table III. Allelic Loss in Pheochromocytomas

\begin{tabular}{|c|c|c|c|c|c|}
\hline Chromosome & Probe/Locus & $\begin{array}{l}\text { Number } \\
\text { informative }\end{array}$ & $\begin{array}{l}\text { Number with } \\
\text { allele loss }\end{array}$ & $\begin{array}{l}\text { Percentage } \\
\text { LOH }\end{array}$ & $\begin{array}{l}\text { Aggregate } \\
\text { LOH }\end{array}$ \\
\hline 10q 11.2 & H4-1RBP/RBP3 & 17 & 0 & $\begin{array}{l}0 \% \\
(0-20)\end{array}$ & \\
\hline $10 \mathrm{q} 11.2$ & pMCK2/D10S15 & 9 & 1 & $\begin{array}{c}11 \%^{\ddagger} \\
(0.3-48)\end{array}$ & $\begin{array}{c}(1 / 22) 5 \% \\
(0.1-23)\end{array}$ \\
\hline 1 p34-p35 & AF3/FUCA1 & 15 & 5 & $\begin{array}{c}33 \%^{*} \\
(12-62)\end{array}$ & \\
\hline $1 \mathrm{p} 36.3$ & p1-79/D1Z2 & 25 & 12 & $\begin{array}{c}48 \% * \\
(28-69)\end{array}$ & $\begin{array}{c}(13 / 31) 42 \% * \\
(25-61)\end{array}$ \\
\hline $3 p 21$ & H3H2/DNF1552 & 24 & 4 & $\begin{array}{l}17 \% * \\
(5-37)\end{array}$ & \\
\hline $3 p 25$ & p627/RAF1 & 18 & 2 & $\begin{array}{l}11 \%^{\ddagger} \\
(1-35)\end{array}$ & $\begin{array}{c}(5 / 31) 16 \%^{*} \\
(5-34)\end{array}$ \\
\hline $17 \mathrm{p} 13.3$ & pYNZ221/D17S5 & 29 & 7 & $\begin{array}{c}24 \%^{*} \\
(10-44)\end{array}$ & $\begin{array}{l}(7 / 29) 24 \%^{*} \\
(10-44)\end{array}$ \\
\hline $22 \mathrm{q} 11.1-\mathrm{q} 11.2$ & p22-34/D22S9 & 18 & 5 & $\begin{array}{c}28 \%^{*} \\
(10-53)\end{array}$ & \\
\hline 22q11.2-qter & pMS3-18/D22S1 & 16 & 5 & $\begin{array}{c}31 \% * \\
(11-59)\end{array}$ & $\begin{array}{c}(9 / 29) 31 \%^{*} \\
(15-31)\end{array}$ \\
\hline $2 p$ & pYNH24/D2S44 & 34 & 1 & $3 \%$ & $(1 / 34) 3 \%$ \\
\hline $5 q 11.2-q 13.3$ & M4/D5S6 & 10 & 0 & $0 \%$ & $(0 / 10) 0 \%$ \\
\hline $13 q 14.2$ & p88R0.6/RB1 & 12 & 0 & $0 \%$ & $(0 / 12) 0 \%$ \\
\hline $16 \mathrm{p} 13.3$ & p3'HVR.64/D16S85 & 34 & 0 & $0 \%$ & $(0 / 34) 0 \%$ \\
\hline
\end{tabular}

Number in parentheses indicate $95 \%$ confidence intervals. ${ }^{\ddagger} P<0.05 ;{ }^{*} P<0.001$. 
Table IV. Allelic Loss in Medullary Thyroid Carcinomas

\begin{tabular}{|c|c|c|c|c|c|}
\hline Chromosome & Probe/Locus & $\begin{array}{c}\text { Number } \\
\text { informative }\end{array}$ & $\begin{array}{l}\text { Number with } \\
\text { allele loss }\end{array}$ & $\begin{array}{c}\text { Percentage } \\
\text { LOH }\end{array}$ & $\begin{array}{c}\text { Aggregate } \\
\text { LOH }\end{array}$ \\
\hline $10 \mathrm{q} 11.2$ & H4-1RBP/RBP3 & 5 & 0 & $\begin{array}{l}0 \% \\
(0-52)\end{array}$ & \\
\hline $10 \mathrm{q} 11.2$ & pMCK2/D10S15 & 4 & 0 & $\begin{array}{l}0 \% \\
(0-60)\end{array}$ & $\begin{array}{l}(0 / 7) 0 \% \\
(0-41)\end{array}$ \\
\hline $1 \mathrm{p} 35-\mathrm{p} 34$ & AF3/FUCA1 & 4 & 1 & $\begin{array}{c}25 \%^{*} \\
(0.6-81)\end{array}$ & \\
\hline $1 \mathrm{p} 36.3$ & p1-79/D1Z2 & 11 & 1 & $\begin{array}{c}9 \% * \\
(0.2-41)\end{array}$ & $\begin{array}{c}(1 / 11) 9 \%^{*} \\
(0.2-41)\end{array}$ \\
\hline $3 p 21$ & $\mathrm{H} 3 \mathrm{H} 2 / \mathrm{DNF} 1552$ & 6 & 0 & $\begin{array}{l}0 \% \\
(0-46)\end{array}$ & \\
\hline $3 \mathrm{p} 25$ & p627/RAF1 & 4 & 0 & $\begin{array}{l}0 \% \\
(0-60)\end{array}$ & $\begin{array}{l}(0 / 7) 0 \% \\
\quad(0-41)\end{array}$ \\
\hline $17 \mathrm{p} 13.3$ & YNZ22.1/D17S5 & 11 & 0 & $\begin{array}{l}0 \% \\
(0-28)\end{array}$ & $\begin{array}{r}(0 / 11) 0 \% \\
(0-28)\end{array}$ \\
\hline $22 \mathrm{q} 11.1-\mathrm{q} 11.2$ & p22-34/D22S9 & 6 & 1 & $\begin{array}{c}17 \%^{*} \\
(0.4-64)\end{array}$ & \\
\hline 22q11.2-qter & pMS3-18/D22S1 & 7 & 1 & $\begin{array}{c}14 \%^{*} \\
(0.4-58)\end{array}$ & $\begin{array}{c}(2 / 10) 20 \%^{*} \\
\quad(3-57)\end{array}$ \\
\hline $2 p$ & YNH24/D2S44 & 8 & 0 & $0 \%$ & $(0 / 8) 0 \%$ \\
\hline $5 q 11.2-q 13.3$ & M4/D5S6 & 7 & 0 & $0 \%$ & $(0 / 7) 0 \%$ \\
\hline $13 q 14.2$ & p88R0.6/RBI & 4 & 0 & $0 \%$ & $(0 / 4) 0 \%$ \\
\hline $16 \mathrm{p} 13.3$ & $3^{1}$ HVR/D16S85 & 9 & 0 & $0 \%$ & $(0 / 9) 0 \%$ \\
\hline
\end{tabular}

Numbers in parentheses indicate $95 \%$ confidence intervals. ${ }^{*} P<0.05$.

only patients with sporadic pheochromocytomas. The patient with familial MTC was also uninformative with both probes.

Other allelic losses: pheochromocytomas. The region of most dramatic allelic loss in the pheochromocytomas was on chromosome 1p (Table III). Overall, 13 of 31 informative pheochromocytomas $(42 \%)$ demonstrated LOH on the distal portion of $1 p$. For comparative purposes, the RB1 locus on 13q as well as several random probes on $2 p, 5 q$, and $16 p$ were used to provide a "background" rate of allelic losses in pheochromocytomas. Pheochromocytomas tended to be chromosomally stable, with our highest background rate being $3 \%$ on $2 \mathrm{p}$. When compared with this background rate of $3 \%$, the $42 \%$ loss noted on $1 \mathrm{p}$ was highly statistically significant $(P<0.001)$.

Fig. $1 a$ shows representative blots demonstrating allelic losses with the 1p probes AF3 and p1-79. As noted earlier, probe p1-79 provided a fingerprint pattern with $20-40$ bands. The high interindividual variability of this probe is related to the presence of different copy numbers of a core sequence spanning $39-40 \mathrm{bp}(21)$. LOH with the probe is scored as positive when one or more bands are deleted in tumor DNA (Fig. 1 $a$ and references [ 34 and 35]). Because the banding pattern may be difficult to interpret, a tumor was scored as positive for $\mathrm{LOH}$ only if it demonstrated $\mathrm{LOH}$ after digestion with two restriction endonucleases, PstI and TaqI. In addition, since even a small amount of DNA degradation makes the banding pattern difficult to interpret, any tumor where this was noted was scored as uninformative. As a control, and to eliminate the possibility of technical artifact, 20 colon carcinomas and 10 osteogenic sarcomas were concomitantly analyzed with p1-79 and none demonstrated LOH (data not shown). Finally, as noted earlier, we performed a detailed densitometric analysis on all tumors scored visually as positive and demonstrated the presence of clearly deleted bands as well as other bands which were reduced in intensity by $50 \%$ (Figs. $2 b$ and 3). Of the tumors positive for $\mathrm{LOH}$ on $1 \mathrm{p}$, one tumor was positive with the more distal p1-79 probe (1p36.3) but negative with the more proximal AF3 probe (1p34-35). In contrast to studies with neuroblastomas demonstrating a correlation between LOH on $1 \mathrm{p}$ and $N-m y c$ gene amplification (35), none of our pheochromocytomas demonstrated amplification of $\mathrm{N}-\mathrm{myc}$ (data not shown).

In addition to $1 \mathrm{p}$, pheochromocytomas also demonstrated significant LOH on 22q, 3p and $17 p$ (Table III, Fig. 1). None of the 12 informative pheochromocytomas had LOH at the RB1 locus, arguing against a role for the retinoblastoma gene in pheochromocytoma formation. Our patient with VHL and pheochromocytoma had no LOH at $3 p$. Both our NF 1 patients were also negative for $\mathrm{LOH}$ on $17 \mathrm{p}$. We analyzed the pheochromocytomas for LOH on 17 p even though the NF 1 gene lies on $17 \mathrm{q} 11.2(17,18)$, because LOH in NF 1 associated tumors may occur principally on $17 p(17)$. Furthermore, the p53 gene, which is involved in colorectal cancer and possibly several other tumors (40), lies on $17 \mathrm{p} 13.1$. We did, however, examine the 7 sporadic pheochromocytomas that demonstrated LOH on $17 p$ (Table III) for LOH on $17 q$ with the probe pTHH59 (17q23-q25.3). Of the 7 tumors, 3 were negative, 3 were uninformative, and only 1 demonstrated $\mathrm{LOH}$ for the $17 \mathrm{q}$ marker.

In Table $\mathrm{V}$, we compare rates of allelic losses in sporadic versus familial pheochromocytomas. As is evident, while the number of familial tumors was relatively small, there appeared to be no differences in the overall rates of allelic losses. 
Table V. Rates of Allelic Losses in Sporadic Versus Familial Pheochromocytomas

\begin{tabular}{|c|c|c|c|c|c|c|}
\hline \multirow[b]{2}{*}{ Chromosome } & \multicolumn{3}{|c|}{ Sporadic } & \multicolumn{3}{|c|}{ Familial } \\
\hline & $\begin{array}{l}\text { Number } \\
\text { informative }\end{array}$ & $\begin{array}{l}\text { Number with } \\
\text { allele loss }\end{array}$ & $\begin{array}{c}\text { Percentage } \\
\text { LOH }\end{array}$ & $\begin{array}{c}\text { Number } \\
\text { informative }\end{array}$ & $\begin{array}{l}\text { Number with } \\
\text { allele loss }\end{array}$ & $\begin{array}{l}\text { Percentage } \\
\text { LOH }\end{array}$ \\
\hline $10 q$ & 19 & 1 & $5 \%$ & 3 & 0 & $0 \%$ \\
\hline $1 p$ & 25 & 11 & $44 \%$ & 6 & 2 & $33 \%$ \\
\hline $3 p$ & 25 & 4 & $16 \%$ & 6 & 1 & $17 \%$ \\
\hline $17 p$ & 24 & 6 & $25 \%$ & 5 & 1 & $20 \%$ \\
\hline $22 q$ & 24 & 8 & $33 \%$ & 5 & 1 & $20 \%$ \\
\hline
\end{tabular}

Thus, while pheochromocytomas showed no significant LOH on chromosome 10 near the MEN 2A locus, there was frequent and statistically significant $\mathrm{LOH}$ on chromosomes $1 \mathrm{p}$, $3 p, 17 p$, and 22q (Fig. 4).

Other allelic losses: MTCs. Table IV shows the data for allelic losses in MTCs. In parallel with the pheochromocytoma data, none of 7 informative MTCs showed LOH in the region of the MEN 2A locus. 1 of 11 MTCs (9\%) showed loss on 1p, a value statistically different from the highest background rate of $3 \%$, but the $95 \%$ confidence intervals included $3 \%$. Similarly, 2 of 10 tumors $(20 \%)$ showed loss on $22 q(P<0.05)$. No LOH was noted on chromosomes $3 \mathrm{p}, 17 \mathrm{p}, 13 \mathrm{q}, 2 \mathrm{p}, 5 \mathrm{q}$, or $16 \mathrm{p}$. Taken together with the pheochromocytoma data, the above numbers suggest a potential role for genes on $1 p$ and $22 q$ in MTC development.

Clinical correlations. To define whether the observed genetic changes in the tumors were functionally important, we compared demographic and clinical characteristics of patients with and without allelic losses on 1p, 3p, 17p, and 22q. Specifcally, we examined whether patient sex, age, benignancy versus malignancy, familial or sporadic tumor, tumor volume, nuclear ploidy status, preoperative urine metanephrine excretion (pheochromocytomas), or preoperative calcitonin level (MTC) were associated with allelic loss in any of the above regions. No such correlations were noted for the MTCs. For the pheochromocytomas, however, increased tumor volume appeared to be associated with $\mathrm{LOH}$ on chromosome $1 \mathrm{p}\left(155 \pm 46 \mathrm{~cm}^{3}\right.$ [mean $\pm \mathrm{SE}$ ] for those with loss vs. $68 \pm 19 \mathrm{~cm}^{3}$ for those without; $P=0.08)$ as well as $3 \mathrm{p}\left(299 \pm 105 \mathrm{~cm}^{3}\right.$ vs. $\left.88 \pm 20 \mathrm{~cm}^{3} ; P=0.04\right)$ and possibly $17 \mathrm{p}\left(172 \pm 69 \mathrm{~cm}^{3}\right.$ vs. $\left.100 \pm 30 \mathrm{~cm}^{3} ; P=0.16\right)$ (Fig. $5 a$ ). While only one of the above correlations achieved statistical significance, the trend in all three instances was clearly in the same direction. In addition, urinary metanephrine excretion was significantly greater in tumors demonstrating $\mathrm{LOH}$ on $1 \mathrm{p}(8.5 \pm 2.3 \mathrm{mg} / 24 \mathrm{~h}$ vs. $2.8 \pm 0.5 \mathrm{mg} / 24 \mathrm{~h} ; P=0.02)$ (Fig. $5 \mathrm{~b}$ ). Thus, tumors with $\mathrm{LOH}$ on $1 \mathrm{p}$ tended to be larger and secreted significantly greater amounts of catecholamines than tumors without $\mathrm{LOH}$ on $1 \mathrm{p}$. LOH on $3 p$ and possibly $17 \mathrm{p}$ also appeared to be correlated with larger tumor volume. No such correlations were noted for LOH on 22q. None of the other parameters examined in the pheochromocytomas showed any correlation with $\mathrm{LOH}$ in any of the above regions.

\section{Discussion}

While the retinoblastoma paradigm is an attractive model for tumorigenesis, it has become clear that not all familial cancer syndromes will follow such a straightforward pattern. FAP and colon carcinoma provide the best alternative model to date in which multiple genes appear to be involved in tumor formation and/or progression (13). With the mapping of the MEN $2 \mathrm{~A}$ gene to the centromeric region on chromosome $10(5,6)$, familial as well as sporadic pheochromocytomas and MTCs were expected to demonstrate allelic losses near that locus. Our

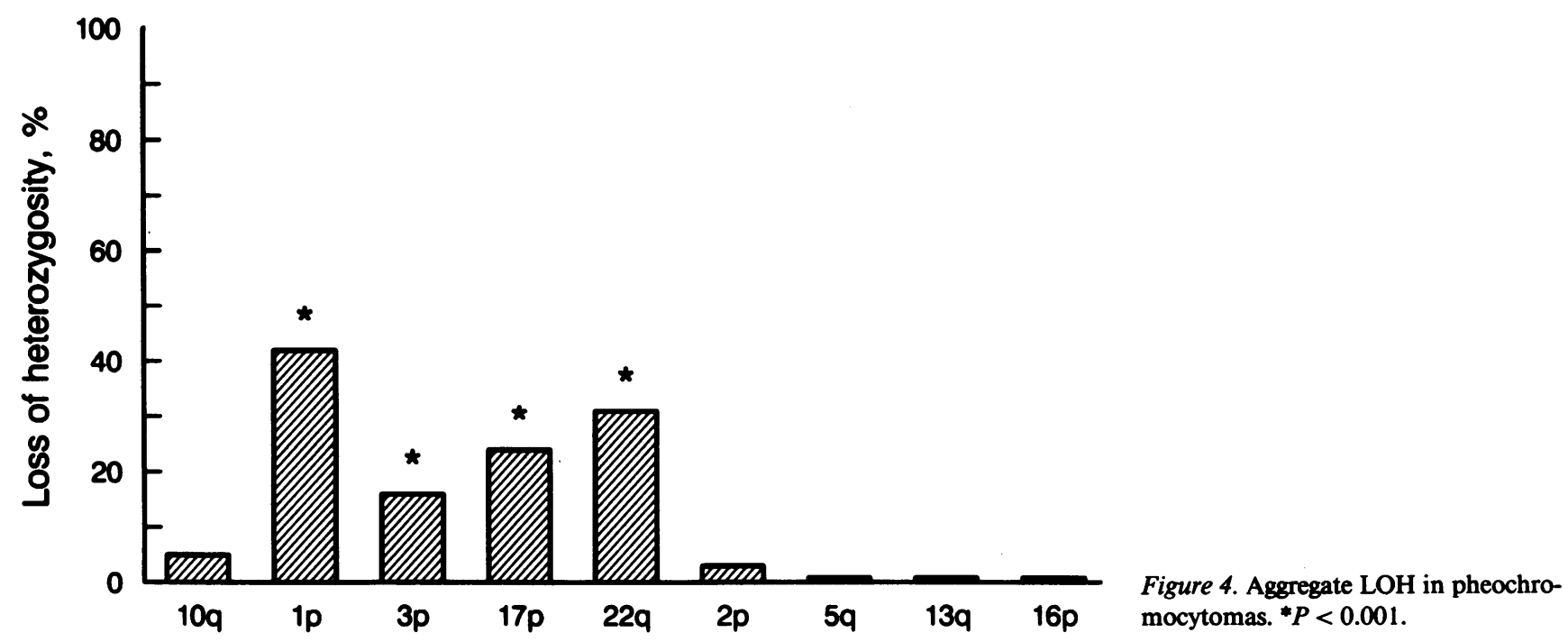




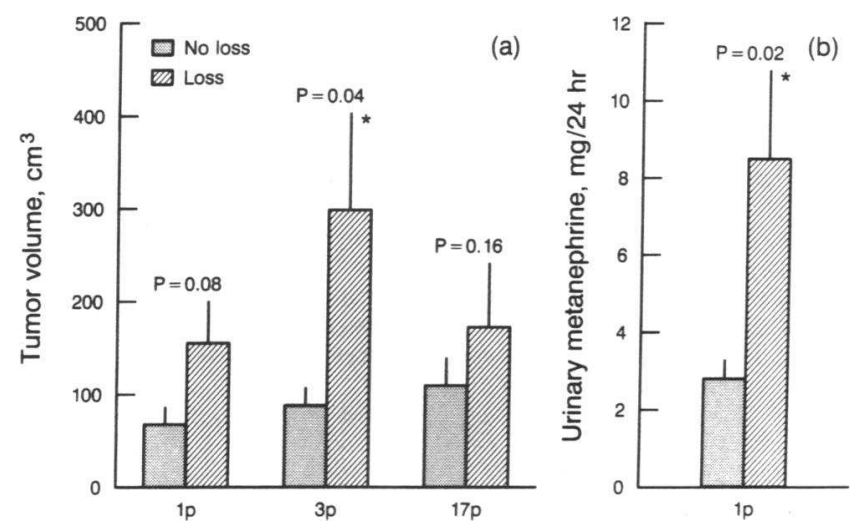

Figure 5. (a) Tumor volume $(\mathrm{cm} 3)$ in pheochromocytomas without loss and with loss on chromosomes $1 \mathrm{p}, 3 \mathrm{p}$, and $17 \mathrm{p}$; and $(b)$ urinary metanephrine excretion $(\mathrm{mg} / 24 \mathrm{~h})$ in pheochromocytomas without $1 \mathrm{p}$ loss and with $1 \mathrm{p}$ loss. ${ }^{*} P<0.05$.

study and two previous ones show conclusively that this is not the case $(11,12)$. In analogy with FAP, Nelkin et al. proposed that in familial pheochromocytomas and MTCs, the inherited abnormality on chromosome 10 may predispose to hyperplasia with subsequent changes on other chromosomes contributing to the transformation to pheochromocytoma or MTC (12). Indeed, $C$ cell and adrenomedullary hyperplasia is a well established premalignant lesion in familial pheochromocytoma and MTC, and may represent the phenotypic consequence of the germ line mutation in the MEN 2A gene $(41,42)$.

If the above model is correct, then one would expect to find other genetic alterations in pheochromocytomas and MTCs that may contribute to tumor formation and/or progression. Because of the scarcity of these tumors, it has been difficult to perform an allelic loss study on these tumors that would have statistical validity. Mathew et al., for example, noted LOH on $1 \mathrm{p}$ in four of six pheochromocytomas and three of eight MTCs (14). In a more recent study, Yang et al. published data on one pheochromocytoma and seven MTCs, with five of their eight tumors demonstrating allelic loss on $1 \mathrm{p}$ (15). Mathew et al. did examine background rates of allelic loss, but because of the small numbers, no formal statistical analysis was possible.

We present here data on a large number of pheochromocytomas demonstrating statistically significant $\mathrm{LOH}$ on $1 \mathrm{p}, 3 \mathrm{p}$, $17 p$, and 22q. These data thus provide support for the multistep model of tumorigenesis proposed by Nelkin for MEN 2-associated tumors. We further demonstrate that $\mathrm{LOH}$ on $1 \mathrm{p}$ is associated with a clinically important tumor marker, namely urinary metanephrine excretion. In addition, $\mathrm{LOH}$ on $1 \mathrm{p}, 3 \mathrm{p}$, and $17 \mathrm{p}$ was associated with increased tumor volume, although the relationship was statistically significant only for $3 p$. The above data suggests that the genetic changes are not random inconsequential events, but rather potentially involved in tumor formation and/or progression. The fact that chromosome $1 p$ and $3 p$ changes were present predominantly in larger tumors suggests that these particular changes may in fact be more important in tumor progression rather than formation. The issue of the specific order in which the genetic changes described in these tumors might occur is beyond the scope of these studies.

Of note, each of the chromosomal regions where we noted LOH has been shown in other studies to harbor a potential tumor suppressor gene. In addition to pheochromocytomas and MTCs, LOH on $1 \mathrm{p}$ has been noted in neuroblastomas (35), breast cancer (34), and familial melanoma (43). Takai et al. (16) have also shown LOH on $22 \mathrm{q}$ in one of nine MTCs and two of five pheochromocytomas tested. Chromosome 22q losses have also been demonstrated in meningiomas and acoustic neuromas (44). Interestingly, the gene for NF 2, which leads to familial acoustic neuromas and meningiomas, has been mapped by linkage analysis to the same region of chromosome 22 that appears to be lost in the above tumors (6).

Chromosome $17 \mathrm{p}$ deletions have most commonly been associated with colorectal cancer and there is strong evidence for involvement of the p53 gene on 17p13-1 in the pathogenesis of colon carcinomas (13). Allelic loss and point mutations involving the p53 gene have also been demonstrated for a variety of tumors including brain, breast, lung, and in a neurofibrosarcoma from a patient with NF 1 (40). In this study, 7 of 29 pheochromocytomas (24\%) demonstrated LOH on 17 p. Further evidence for involvement of the p53 gene in the pathogenesis of pheochromocytomas would come from direct sequence analysis of the p53 gene, particularly in the 7 tumors demonstrating allelic losses on $17 \mathrm{p}$. These studies are currently in progress.

Chromosome $3 p$ deletions have been described in renal cell carcinomas (45) as well as lung carcinomas (46). In addition, the gene for VHL, which leads to inherited retinal angiomas, cerebellar hemangioblastomas, renal carcinomas, and pheochromocytomas, has been mapped to the distal portion of $3 p$ by linkage analysis (8). Our studies suggest that some sporadic pheochromocytomas do harbor allelic losses in the region of this presumed tumor suppressor gene.

While the presence of allelic losses on chromosome 1p, 22q, $17 p$, and $3 p$ suggest a mechanism involving loss of tumor suppressor genes, several alternative interpretations are also possible. As Mathew et al. have suggested for chromosome 1 (14), it is possible that mutations in oncogenes on one of the above chromosomes followed by loss of the corresponding wild-type alleles may then lead to cooperation between the mutant oncogenes and the MEN 2 gene. While not providing mechanistic explanations, our findings do suggest potential chromosomal regions that may harbor genes important in pheochromocytoma development.

The statistical validity of our analysis depends to some degree on how accurately we succeeded in assessing background rates of loss in these tumors. In assessing three essentially random loci $(2 \mathrm{p}, 5 \mathrm{q} 11.2-\mathrm{q} 13.3,16 \mathrm{p} 13.3)$ as well as the $R \mathrm{~b}$ locus (13q14.2), the highest rate of loss we observed was $3 \%$. No random losses were observed in the MTCs. These data argue that these tumors tend to be chromosomally stable, thus permitting the type of statistical analysis used in this study. Further support for the chromosomal stability of these tumors comes from the study of Landsvater et al. (11), where only 4 loci of 241 informative comparisons (on chromosomes other than 10 or 1) in 14 pheochromocytomas and 28 MTCs showed evidence for $\mathrm{LOH}$. Expressing our data in analogous terms, only 1 of 118 informative comparisons in the background probes (2p, 5q, 13q, 16p) showed LOH (Tables III and IV).

In summary, these studies provide evidence for significant $\mathrm{LOH}$ in pheochromocytomas on chromosome $1 \mathrm{p}, 22 \mathrm{q}, 17 \mathrm{p}$, and $3 p$. Combined with the lack of allelic loss near the MEN $2 \mathrm{~A}$ locus, these data provide further support for the hypothesis 
that tumorigenesis in MEN 2A-associated tumors may follow a more complex pathway than the simple retinoblastoma paradigm. Our data do not exclude the involvement of other, as yet undefined, genetic alterations that may contribute to tumor formation. These studies do, however, provide important clues for future studies aimed at a more precise elucidation of the genetic changes in these tumors.

\section{Acknowledgments}

The authors thank Dr. B. N. White for the p22-34 probe, Dr. R. White for the pMS3-18 and pTHH59 probes, Dr. X. Estivill for the KM.19 probe, and Dr. T. Dryja for the p88R0.6 probe. All other probes were obtained from the American Type Culture Collection. The authors would also like to thank Dr. Richard M. Weinshilboum for access to the pheochromocytomas that had been frozen at the Mayo Clinic over the past eight years.

The authors would also like to thank Dr. Hunter Heath III, and Dr. Norman L. Eberhardt for their suggestions and critiques, as well as Sue Beilke for secretarial assistance.

This work was supported by a grant from the Mayo Foundation.

\section{References} 402.

1. Ponder, B. 1988. Gene losses in human tumours. Nature (Lond.). 335:400

2. Lee, W. H., J. Shew, F. D. Hong, T. W. Sery, L. A. Donoso, L. Young, R. Bookstein, and E. Y. P. Lee. 1987. The retinoblastoma susceptibility gene encodes a nuclear phosphoprotein associated with DNA binding activity. Nature (Lond.). 329:642-645.

3. Friend, S. H., T. P. Dryja, and R. A. Weinberg. 1988. Oncogenes and tumor-suppressing genes. N. Engl. J. Med. 318:618-622.

4. Larsson, C., B. Skogseid, K. Oberg, Y. Nakamura, and M. Nordenskjold. 1988. Multiple endocrine neoplasia type 1 gene maps to chromosome 11 and is lost in insulinoma. Nature (Lond.). 332:85-87.

5. Mathew, C. G. P., K. S. Chin, D. F. Easton, K. Thorpe, C. Carter, G. I Liou, S. L. Fong, C. D. B. Bridges, H. Hank, A. C. Niewenhuijzen Kruseman, S Schifter, H. H. Hansen, H. Telenins, M. Telenins-Berg, and B. A. J. Ponder. 1987. A linked genetic marker for multiple endocrine neoplasia type $2 A$ on chromosome 10. Nature (Lond.). 328:527-530.

6. Simpson, N. E., K. K. Kidd, P. J. Goodfellow, H. McDermid, S. Myers, J. R. Kidd, C. E. Jackson, A. M. V. Duncan, L. A. Farrer, K. Brasch, C. Castiglione, M. Genel, J. Gertner, C. R. Greenberg, J. F. Gusella, J. J. A. Holden, and B. N. White. 1987. Assignment of multiple endocrine neoplasia type 2A to chromosome 10 by linkage. Nature (Lond.). 328:528-530.

7. Wertelecki, W., G. A. Rouleau, D. W. Superneau, L. W. Forehand, J. P. Williams, J. L. Haines, and J. F. Gusella. 1988. Neurofibromatosis 2: Clinical and DNA linkage studies of a large kindred. $N$. Engl. J. Med. 319:278-283.

8. Seizinger, B. R., G. A. Rouleau, L. J. Ozelius, A. H. Lane, G. E. Farmer, J. M. Lamiell, J. Haines, J. W. M. Yuen, D. Collins, D. Majoor-Krakaner, et al. 1988. Von Hippel-Lindau disease maps to the region of chromosome 3 associated with renal cell carcinoma. Nature (Lond.). 332:268-269.

9. Bodmer, W. F., C. J. Bailey, J. Bodmer, H. J. R. Bussey, A. Ellis, P. Gorman, F. C. Lucibello, V. A. Murday, S. H. Rider, P. Scrambler, D. Sheer, E. Solomon, and N. K. Spur. 1987. Localization of the gene for familial adenomatous polyposis on chromosome 5. Nature (Lond.). 328:614-616.

10. Leppert, M., M. Dobbs, P. Scrambler, P. O'Connell, Y. Nakamura, D. Stauffer, S. Woodward, R. Burt, J. Hughes, E. Gardner, M. Lathrop, J. Wasmuth, J. M. Lalouel, and R. White. 1987. The gene for familial polyposis coli maps to the long arm of chromosome 5. Science (Wash. DC). 238:1411-1413.

11. Landsvater, R. M., C. G. P. Mathew, B. A. Smith, E. M. Marcus, G. T. Meerman, C. J. M. Lips, R. A. Geerdink, Y. Nakamura, B. A. J. Ponder, and C. H. C. M. Buys. 1989. Development of multiple endocrine neoplasia type 2A does not involve substantial deletions of chromosome 10. Genomics. 4:246-250.

12. Nelkin, B. D., Y. Nakamura, R. W. White, A. C. de Bustros, J. Herman, S. A. Wells, Jr., and S. B. Baylin. 1989. Low incidence of loss of chromosome 10 in sporadic and hereditary human medullary thyroid carcinoma. Cancer Res. 49:4114-4119.

13. Vogelstein, B., and E. R. Fearon. 1990. A genetic model for colorectal tumorigenesis. Cell. 61:759-767.

14. Mathew, C. G. P., B. A. Smith, K. Thorpe, Z. Wong, N. J. Royle, A. J.
Jeffreys, and B. A. J. Ponder. 1987. Deletion of genes on chromosome 1 in endocrine neoplasia. Nature (Lond.). 328:524-526.

15. Yang, K. P., C. V. Nguyen, S. C. Castillo, and N. A. Samaan. 1990. Deletion mapping on the distal third region of chromosome $1 \mathrm{p}$ in multiple endocrine neoplasia type IIA. Anticancer Res. 10:527-534.

16. Takai, S. H., H. Tateishi, I. Nishisho, T. Miki, K. Motomura, A. Miuauchi, M. Kato, T. Ikeuchi, K. Yamamoto, M. Okazuki, M. Yamamoto, T. Nunjo, Y. Kumahara, and T. Mori. 1987. Loss of genes on chromosome 22 in medullary thyroid carcinoma and pheochromocytoma. Jpn. J. Cancer Res. 78:894-898.

17. Cawthon, R. M., R. Weiss, G. Xu, D. Viskochil, M. Culver, J. Stevens, M. Robertson, D. Dunn, R. Gesteland, P. O'Connell, and R. White. 1990. A major segment of the neurofibromatosis type 1 gene: cDNA sequence, genomic structures, and point mutations. Cell. 62:193-201.

18. Wallace, M. R., D. A. Marchuk, L. B. Anderson, R. Letcher, H. M. Odeh A. M. Saulino, J. W. Fountain, A. Brereton, J. Nicholson, A. L. Mitchell, B. H. Brownstein, and F. S. Collins. 1990. Type 1 neurofibromatosis gene: identification of a large transcript disrupted in three NF1 patients. Science (Wash. DC). 249:181-186.

19. Southern, E. 1975. Detection of specific sequences among DNA fragments separated by gel electrophoresis. J. Mol. Biol. 98:503-517.

20. Fowler, M. L. H. Nakai, M. G. Byers, H. Fukushima, R. L. Eddy, W. M Henry, L. L. Haley, S. O'Brien, and T. B. Shows. 1986. Chromosome 1 localization of the human alpha-L-fucosidase structural gene with a homologous site on chromosome 2. Cytogenet. Cell Genet. 43:103-108.

21. Buroker, N., R. Bestwick, G. Haight, R. E. Magenis, and M. Litt. 1987. A hypervariable repeated sequence on chromosome 1p 36. Hum. Genet. 77:175181 .

22. Nakamura, Y., S. Gillilan, P. O'Connell, M. Leppert, G. M. Lathrop J. M. Lalouel, and R. White. 1987. Isolation and mapping of a polymorphic DNA sequence pYNH24 on chromosome 2 (D2S44). Nucleic Acids Res. 15:10073.

23. Carriet, B., H. M. Welch, N. J. Parry-Jones. 1986. Sequences homologous to the human D1S1 locus present on human chromosome 3. Am. J. Hum. Genet. 38:428-436.

24. Bonner, T., S. J. O'Brien, W. G. Nash, U. R. Rapp, C. C. Morton, and P. Leder. 1984. The human homologs of the raf (mil) oncogene are located on human chromosomes 3 and 4. Science (Wash. DC). 223:71-74.

25. Dietzsch, E., A. E. Retief, M. J. Lotze, L. Warnich, D. L. Nicholson, M. F. Fox, J. Fricke, L. De Plessiss, and C. J. J. Oosthuizen. 1986. An annonymous human single copy genomic clone, D5S6(M4) on chromosome 5 identifies a three allele RFLP. Nucleic Acids Res. 14:1923.

26. Chin, K. S., C. G. P. Mathew, S. L. Fong, C. D. B. Bridges, and B. A. J. Ponder. 1988. Sty 1 RFLP recognised by a human IRBP cDNA localised to chromosome 10. Nucleic Acids Res. 16:1645.

27. Nakamura, Y., M. Carlson, K. Krapcho, J. Gill, P. O’Connell, M. Leppert, G. M. Lathrop, J. M. Lalouel, and R. White. 1988. Isolation and mapping of a polymorphic DNA sequence pMCK2 on chromosome 10. Nucleic Acids Res. 16:374.

28. Wiggs, J., M. Nordenskjold, D. Yandell, J. Rapaport, V. Grondin, M. Janson, B. Werelins, R. Petersen, A. Craft, K. Reidel, R. Liberfarb, D. Walton, W. Wilson, and T. P. Dryja. 1988. Prediction of the risk of hereditary retinoblastoma, using DNA polymorphisms within the retinoblastoma gene. $N$. Engl. J. Med. 318:151-157.

29. Higgs, D. R., J. S. Wainscoat, J. Flint, A. V. S. Hill, S. L. Thein, R. D. Nicholls, H. Teal, H. Ayynb, T. E. A. Peto, A. G. Falusi, A. P. Jarman, J. B. Clegg, and D. J. Weatherall. 1986. Analysis of human adult alpha-globin gene cluster reveals a highly informative genetic locus. Proc. Natl. Acad. Sci. USA. 83:51655169.

30. Lothe, R. A., Y. Nakamura, S. Woodward, T. Gedd-Dahl, Jr., and R. White. 1988. VNTR (variable number of tandem repeats) markers show loss of chromosome 17p sequences in human colorectal carcinomas. Cytogenet. Cell Genet. 48:167-169.

31. Nakamura, Y., T. Holm, S. Gillilan, M. Leppert, P. O'Connell, G. M. Lathrop, J. M. Lalouel, and R. White. 1988. Isolation and mapping of a polymorphic DNA sequence (pTHH59) on chromosome 17q(D17S4). Nucleic Acids Res. 16:3598.

32. McDermid, H., A. M. V. Duncan, K. Brasch, J. Burn, J. J. A. Holden, N. Kardon, E. Magenis, B. Noel, A. Schinzel, I. Teshima, and B. N. White. 1985. Molecular analysis of the supernumerary chromosome in Cat Eye Syndrome. Cytogenet. Cell Genet. 40:695-696.

33. Barker, D., M. Schafer, and R. White. 1984. Restriction sites containing CpG show a higher frequency of polymorphism in human DNA. Cell. 36:131138.

34. Genuardi, M., H. Tsihira, D. E. Anderson, and G. F. Saunders. 1989. Distal deletion of chromosome $1 \mathrm{p}$ in ductal carcinoma of the breast. Am. J. Hum. Genet. 45:73-82.

35. Fong C., N. C. Dracopoli, P. S. White, P. T. Merrill, R. C. Griffith, D. E. Honsman, and G. M. Brodeur. 1989. Loss of heterozygosity fo the short arm of chromosome 1 in human neuroblastomas: Correlation with $\mathrm{N}$-myc amplification. Proc. Natl. Acad Sci. USA. 86:3753-3757. 
36. Stanton, L. W., M. Schwab, and J. M. Bishop. 1986. Nucleotide sequence of the human N-myc gene. Proc. Natl. Acad. Sci. USA. 83:1772-1776.

37. Estivill, X., P. J. Scrambler, B. J. Wainwright, K. Hawley, P. Frederick, M Schwartz, M. Baiget, J. Kere, R. Williamson, and M. Farral. 1987. Patterns of polymorphism and linkage disequilibrium for cystic fibrosis. Genomics. 1:257263.

38. Ryan, J. J., I. D. Hay, C. S. Grant, L. M. Rainwater, G. M. Farrow, and J. R. Goellner. 1988. Flow cytometric DNA measurements in benign and malignant Hurthle cell tumors of the thyroid. World J. Surg. 12:482-287.

39. Dean, P. J., and J. H. Jett. 1974. Mathematical analysis of DNA distribution derived from flow microfluorometry. J. Cell Biol. 60:523-528.

40. Nigro, J. M., S. J. Baker, A. C. Preisinger, J. M. Jessup, R. Hostetter, K. Cleary, S. H. Bigner, N. Davidson, S. Baylin, P. Devilee, T. Glover, F. S. Collins, A. Weston, R. Modali, C. C. Harris, and B. Vogelstein. 1989. Mutation in the p53 gene occur in diverse human tumour types. Nature (Lond.). 342:705-708.

41. Wolfe, H. J., K. E. W. Melvin, S. J. Cervi-Skinner, A. A. A. Sandi, J. F. Juliar, C. E. Jackson, and A. H. Tashjian, Jr. 1973. C-cell hyperplasia preceding medullary thyroid carcinoma. $N$. Engl. J. Med. 289:437-441.
42. DeLellis, R. A., H. J. Wolfe, R. F. Gagel, Z. T. Feldman, H. H. Miller, D. L. Gang, and S. Reichlin. 1976. Adrenal medullary hyperplasia: a morphometric analysis in patients with familial medullary thyroid carcinoma. Am. J. Pathol. 83:177-196.

43. Bale, S. J., N. C. Dracopoli, M. A. Tucker, W. H. Clark, M. C. Fraser, B. Z. Stanger, P. Green, H. Donis-Keller, D. E. Housman, and M. H Greene. 1989. Mapping the gene for hereditary cutaneous malignant melanoma-dysplastic nevus to chromosome 1p. N. Engl. J. Med. 320:1367-1372.

44. Okazaki, M. I. Nichisho, $H$. Tateishi, K. Motomura, M. Yamamoto, T. Miki, T. Hayakawa, S. Takai, T. Honjo, and T. Mori. 1988. Loss of genes on the long arm of chromosome 22 in human meningiomas. Mol. Biol. Med. 5:15-22.

45. Kovacs, G., R. Erlandsson, F. Boldog, S. Ingvarsson, R. Müller-Brechlin, G. Klein, and J. Sumeg. 1988. Consistent chromosome 3p deletion and loss of heterozygosity in renal cell carcinoma. Proc. Natl. Acad. Sci. USA. 85:15711575 .

46. Sithanandam, G., M. Dean, V. Brennscheidt, T. Beck, A. Gazdar, J. D. Minna, H. Branch, B. Zbar, and V. R. Rapp. 1989. Loss of heterozygosity at the c-raf locus in small cell lung carcinoma. Oncogene. 4:451-455. 